\title{
Optimization of a Product Batch Quantity
}

\author{
Tomaž Berlec* - Janez Kušar - Janez Žerovnik - Marko Starbek \\ University of Ljubljana, Faculty of Mechanical Engineering, Slovenia
}

Companies encounter various challenges when entering the global market, one of the most significant being the calculation of the optimal batch quantity of a product. This paper explains how to calculate the optimal batch quantity using first the basic model, and then the extended model that takes into account the tied-up capital in a production, in addition to the costs of changing the batch and storage costs. There is a case study of calculating the optimal batch quantity using the basic and extended models, together with conclusions regarding when either of the two models should be used. For optimal batch quantities we also calculated lead times, corresponding costs of tied-up capital per piece, and the difference between costs per piece when using the basic and extended models.

Keywords: optimal batch, tied-up capital, storage costs, time per unit, setup time, lead time, turnaround time, interoperation time

\section{INTRODUCTION}

The goal of calculating the optimal batch quantity of a product is that the product is produced in the required quantity and required quality at the lowest cost [1] to [3].

There are basically two options of planning the batch quantity [4]:

- planning a large batch of a product in long intervals,

- planning a small batch of a product in short intervals.

The advantages of planning a large batch of product are:

- price advantage of ordering a large batch (low cost, protection against raising prices, volume rebate),

- lower administrative costs,

- lower costs of tests and shipping,

- low risk of interruption of production because of the large stock.

The disadvantages of planning a large batch are:

- high tied-up capital,

- high storage costs of product inventory.

The advantages of planning a small batch of product are:

- low tied-up capital,

- low storage costs of product inventory,

- high flexibility if quantities change at suppliers and buyers.

The disadvantages of planning a small batch are:

- the costs of frequent ordering,

- high risk of interruption of production because of a small product inventory.

Somewhere between the large and small batch quantity is the optimal batch quantity, i.e. the quantity in which the cost per product unit is the lowest.
Aggterleky [4] describes the optimal planning planes and the meaning of under- and over planning, and the influence of the reduction of total cost. Wiendahl [5] uses Harris and Andler's equation for the determination of the optimal quantity. Härdler [6] takes into account the costs of storage and delivery in determining the optimal batch quantity. Muller [7] and Piasecki [8] assert that inventory management is explained only with the basics of an optimal quantity calculation. So, in comparison to the aforementioned papers, where only the determination of the optimum quantity is given, our model is expanded to include the impact of the flow time on the batch quantity or stock.

\section{ECONOMIC ORDER QUANTITY - BASIC MODEL}

Changing the product batch (hereinafter referred to as 'order') causes two types of costs [9]:

- order change costs,

- storage costs.

Order change costs include costs for preparing documentation, costs of control and input of goods, costs of workers' wages, costs of setting up the machines, and costs of producing samples.

The order, therefore, causes annual costs, known as order change costs $S_{M e n}$. The higher the ordered quantity is, the lower the influence of the order change costs is (Fig. 1a). The order also causes storage costs, which include the costs of interest on the bound capital and warehouse costs.

The order therefore also causes annual storage costs $S_{S k l}$, which increase proportionally as the ordered quantity increases (Fig. 1b).

The sum of the annual order change costs and storage costs has the minimum value of the total costs $S_{V s o, \min }$ at the optimal batch quantity $x_{O p t}$ (basic model) (Fig. 1c). 


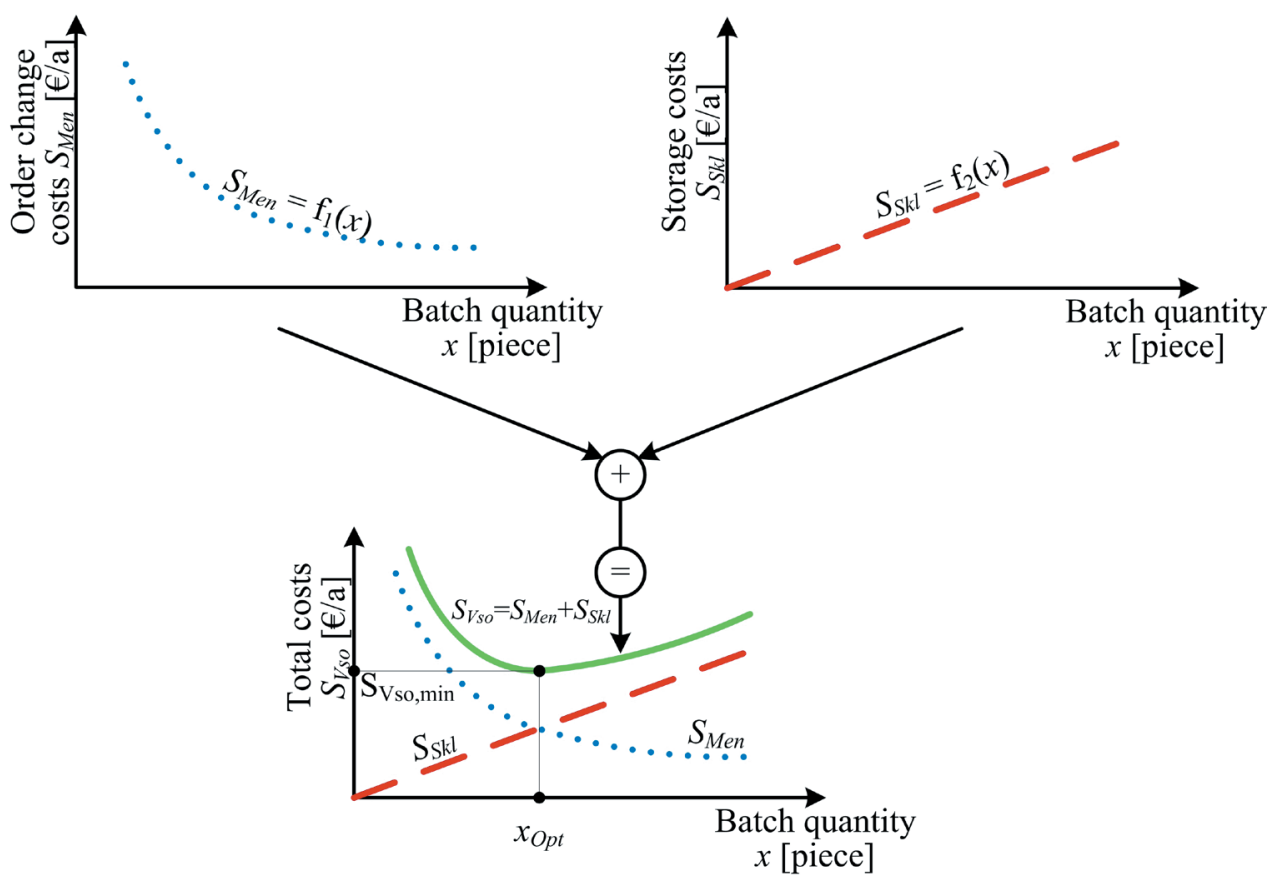

Fig. 1. a) order change costs, b) Storage costs of order, c) Optimal batch quantity $x_{\text {Opt }}$ in the basic model

The optimal batch quantity in the basic model [6] and [7] can be calculated by using the following sequence of steps:

Step 1: Calculation of annual order change costs:

$$
S_{M e n}=\frac{L}{x} \cdot S_{M e n},
$$

where $S_{M e n}$ are annual order change costs [€/a], $L$ annual needs [piece/a], $x$ batch quantity [piece], and $s_{\text {Men }}$ order change costs $[€]$.

Step 2: Calculation of annual storage costs:

Pulse inflow and steady outflow of goods is assumed (Fig. 2). The annual storage costs depend on the warehouse inventory:

$$
S_{S k l}=\frac{x}{2} \cdot s_{O b d} \cdot p,
$$

where $S_{S k l}$ are storage costs [€/a], $x$ batch quantity [piece], $s_{O b d}$ processing costs per piece [€/piece], and $p$ interest rate of tied-up capital [1/a].

Step 3: Calculation of total annual order costs:

$$
S_{V s o}=S_{M e n}+S_{S k l}=\frac{L}{x} \cdot s_{M e n}+\frac{x}{2} \cdot s_{O b d} \cdot p .
$$

Step 4: Calculation of economic order quantity $x_{O p t}:$

The economic order quantity (i.e. the minimum value of this function) can be found by differentiation.

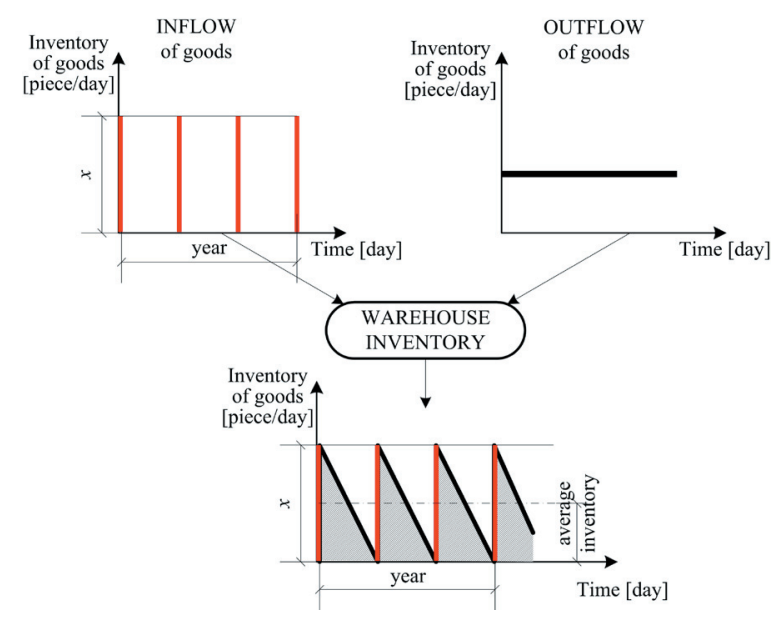

Fig. 2. Storage inventory of goods

Differentiating $S_{V s o}$ with respect to $x$ and then equating to zero, we get:

$$
\frac{\mathrm{d} S_{V s o}}{\mathrm{~d} x}=-\frac{L}{x^{2}} \cdot s_{M e n}+\frac{s_{O b d} \cdot p}{2}=0 .
$$

The optimal batch quantity $x_{\text {Opt }}$ :

$$
x_{\text {Opt }}=\sqrt{\frac{2 \cdot L \cdot s_{M e n}}{s_{O b d} \cdot p}},
$$

where $x_{O p t}$ are optimal batch quantity [piece], $L$ annual needs [piece/a], $s_{M e n}$ order change costs $[€], s_{O b d}$ 
processing costs per piece [€/piece], and $p$ interest rate of tied-up capital [1/a].

The interest rate of tied-up capital $p$ is calculated on the basis of the bank interest rate for a long-term loan with additional interest using the VDI 3330 guidelines (Table 1).

Table 1. Interest rate of tied-up capital, in [\%]

\begin{tabular}{lc}
\hline A. Bank interest rate for a long-term capital loan & 7.15 \\
\hline \multicolumn{2}{l}{ Additional interests: } \\
\hline limitation & 3 to 5 \\
\hline losses caused by break or rupture & 2 to 4 \\
\hline transport & 2 to 4 \\
\hline storage and write-off & 1.5 to 2 \\
\hline warehouse management & 1 to 2 \\
\hline control & 1 to 2 \\
\hline insurance & 0.5 to 1 \\
\hline B. SUM OF ADDITIONAL INTERESTS & 11 to 20 \\
\hline INTEREST RATE OF TIED-UP CAPITAL $p=A+B$ & 18.15 to 27.15 \\
\hline
\end{tabular}

\section{ECONOMIC ORDER QUANTITY - EXTENDED MODEL}

In our basic model for the calculation of optimal batch quantity only the order change costs $S_{M e n}$ and storage costs $S_{S k l}$ were taken into account.

Analysis of the diagram of the flow of orders through work systems [10] revealed that during the processing of the observed order in a given workplace, other orders have to wait for the release of capacities, which in turn causes additional costs related to the tied-up capital in production (Fig. 3).

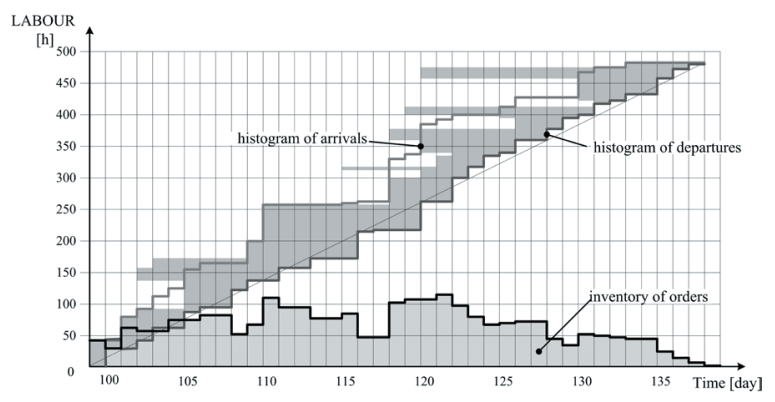

Fig. 3. Flow diagram showing inventory of orders

Tying-up the capital in the material flow from a supplier through production to the customer [11] is shown in Fig. 4.

After having carried out an analysis of the flow diagram showing the status of orders, and a diagram of tying-up the capital on the path from supplier to customer, Nyhuis and Fronla [12] concluded that when calculating the economic order quantity, in addition to the cost of order change $S_{M e n}$ and storage costs $S_{S k l}$, it would also be necessary to take into account the costs of execution of operations of an order in the production $S_{I z v}$ and costs of disposal (transition) $S_{P r e}$.

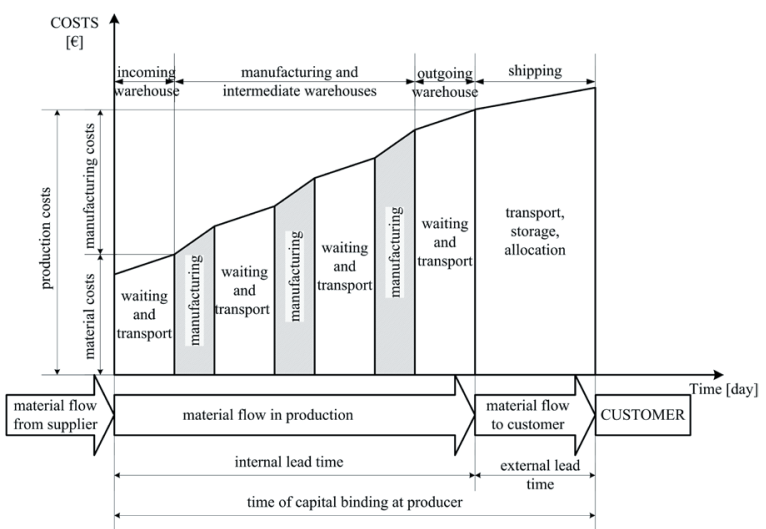

Fig. 4. Tying-up the capital in the material flow from supplier to customer

The optimal batch quantity in the extended model $x_{O p t}^{*}$ will be the one in which the sum of annual order change costs, the storage costs, the costs of execution of operations of an order, and the transition costs will have the minimum value (Fig. 5).

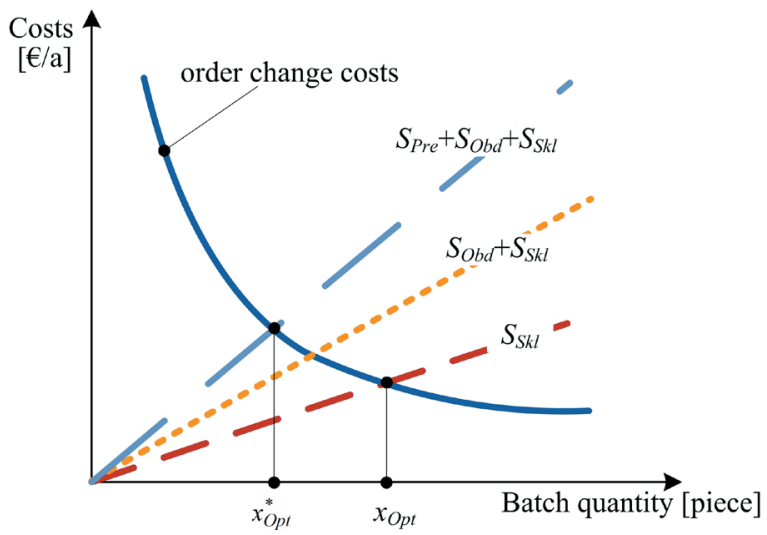

Fig. 5. Optimal batch quantity $x_{O p t}^{*}$ in the extended model

The optimal batch quantity $x_{O p t}^{*}$ in the extended model is calculated in the following sequence:

Step 1: Calculation of annual order change costs:

$$
S_{M e n}^{*}=\frac{L}{x^{*}} \cdot S_{M e n},
$$

where $S_{\text {Men }}^{*}$ are annual order change costs $[€ / \mathrm{a}], L$ annual needs [piece/a], $x^{*}$ batch quantity [piece], $s_{M e n}$ order change costs $[€]$. 
Step 2: Calculation of annual storage costs:

Pulse inflow and steady outflow of goods is assumed (Fig. 3). The annual storage costs are:

$$
S_{S k l}^{*}=\frac{x^{*}}{2} \cdot S_{O b d} \cdot p,
$$

where $S_{S k l}^{*}$ are annual storage costs $[€ / \mathrm{a}], x^{*}$ batch quantity [piece], $s_{\text {Obd }}$ processing costs per piece [€/ piece], $p$ interest rate of tied-up capital [1/a].

Step 3: Calculation of annual costs of orderprocessing times:

The one-dimensional lead time of an order operation, consisting of the turnaround time of the operation $T_{I z v}$ and the interoperation time $T_{P r e}$ is shown in Fig. 6 [10].

\begin{tabular}{|c|c|c|}
\hline & & \\
\hline & $T_{p}$ & $t_{\text {Obd }}$ \\
\hline & & $T_{\text {Izv }}$ \\
\hline$T_{\text {Pre }}$ & & \\
\hline \multicolumn{2}{|c|}{$T_{O}$} & \\
\hline
\end{tabular}

Fig. 6. Lead time of operation; $T_{p}$ setup time [min], $t_{\text {obd }}$ manufacturing time [min], $T_{l z V}$ turnaround time [day], $T_{\text {Pre }}$ interoperation time [day], $T_{0}$ lead time of operation [day]

Known order-processing times allow for a calculation of annual costs due to operation-execution times $S_{I z v}^{*}$ :

$$
S_{I z v}^{*}=\frac{\left(s_{M a t}+S_{O b d}\right) \cdot L \cdot p}{2 \cdot R C} \cdot \sum T_{I z v},
$$

where $S_{I z v}^{*}$ are annual costs arising from the operationexecution of an order $[€ / \mathrm{a}], s_{\text {Obd }}$ processing costs per piece [€/piece], $s_{M a t}$ material costs per piece [€/piece], $L$ annual needs [piece/a], $p$ interest rate of tied-up capital [1/a], $R C$ available time [day/a], $\Sigma T_{I z v}$ total operation-execution time [day].

Step 4: Calculation of annual costs due to interoperation time:

$$
S_{\mathrm{Pr} e}^{*}=\frac{\left(s_{M a t}+s_{\text {Obd }}\right) \cdot L \cdot p}{2 \cdot R C} \cdot \sum T_{\mathrm{Pr} e},
$$

where $S_{\mathrm{Pr} e}^{*}$ are annual costs due to interoperation time $[€ / \mathrm{a}]$, and $\Sigma T_{P r e}$ sum of interoperation times [Wd].

Step 5: Calculation of total annual costs $S_{V s o}^{*}$ :

$$
S_{V s o}^{*}=S_{M e n}^{*}+S_{S k l}^{*}+S_{I z v}^{*}+S_{\mathrm{Pr} e}^{*},
$$

$$
\begin{gathered}
S_{V s o}^{*}=\frac{L}{x^{*}} \cdot s_{M e n}+\frac{x^{*}}{2} \cdot s_{O b d} \cdot p+ \\
\quad+\frac{\left(s_{M a t}+s_{O b d}\right) \cdot L \cdot p}{2 \cdot R C} \cdot \sum T_{I z v}+ \\
\quad+\frac{\left(s_{M a t}+s_{O b d}\right) \cdot L \cdot p}{2 \cdot R C} \cdot \sum T_{\mathrm{Pr} e}, \\
S_{V s o}^{*}=\frac{L}{x^{*}} \cdot s_{M e n}+\frac{x^{*}}{2} \cdot s_{O b d} \cdot p+ \\
+\frac{\left(s_{M a t}+s_{O b d}\right) \cdot L \cdot p}{2 \cdot R C} \cdot\left[\sum T_{I z v}+\sum T_{\mathrm{Pr} e}\right] .
\end{gathered}
$$

The material flow rate $S T$ is defined by the $\mathrm{Eq}(9)$ :

$$
S T=\frac{\sum T_{I z v}+\sum T_{\mathrm{Pre}}}{T_{I z v}} .
$$

Therefore, Eq. (9) can be transformed to:

$$
\sum T_{I z v}+\sum T_{\mathrm{Pre}}=S T \cdot \sum T_{I z v} .
$$

The total time of the operation-execution of an order is defined as:

$$
\sum T_{I z v}=\sum \frac{T_{p}+x^{*} \cdot t_{e 1}}{60 \cdot K A P}
$$

where $\Sigma T_{I z v}$ is total time of operation execution of an order [day], $T_{p}$ setup time [min], $t_{e l}$ time per unit [min/ piece], $K A P$ daily capacities [h/day], $x^{*}$ batch quantity [piece].

If Eqs. (10) and (11) are inserted in Eq. (8), the function for calculating the total order-dependent costs is transformed to:

$$
\begin{aligned}
S_{V S o}^{*} & =\frac{L}{x^{*}} \cdot s_{M e n}+\frac{x^{*}}{2} \cdot s_{O b d} \cdot p+ \\
& +\frac{\left(s_{M a t}+s_{O b d}\right) \cdot L \cdot p}{2 \cdot R C} \cdot S T \cdot \sum \frac{T_{p}+x^{*} \cdot t_{e 1}}{60 \cdot K A P},
\end{aligned}
$$

Step 6: Calculation of the economic order quantity $x_{O p t}^{*}$ :

The minimum value of the function $S_{V s o}^{*}$ can be found by differentiation. Differentiating $S_{V s o}^{*}$ with respect to $x^{*}$ and then equating to zero, we get:

$$
\begin{aligned}
\frac{d S_{V S o}^{*}}{d x^{*}} & =-\frac{L}{\left(x^{*}\right)^{2}} \cdot S_{M e n}+\frac{s_{O b d} \cdot p}{2}+ \\
& +\frac{\left(s_{M a t}+s_{O b d}\right) \cdot L \cdot p}{2 \cdot R C} \cdot S T \cdot \sum \frac{t_{e 1}}{60 \cdot K A P}=0,
\end{aligned}
$$




$$
\frac{2 \cdot L}{\left(x^{*}\right)^{2}} \cdot s_{M e n}=s_{O b d} \cdot p+\frac{\left(s_{M a t}+s_{O b d}\right) \cdot L \cdot p}{60 \cdot R C} \cdot S T \cdot \sum \frac{t_{e 1}}{K A P}
$$

The economic order quantity (i.e. optimal batch quantity) is therefore:

$$
x_{O p t}^{*}=\sqrt{\frac{2 \cdot L \cdot s_{M e n}}{s_{O b d} \cdot p+\frac{\left(s_{M a t}+s_{O b d}\right) \cdot L \cdot p}{60 \cdot R C} \cdot S T \cdot \sum \frac{t_{e 1}}{K A P}}} .
$$

where $x_{O p t}^{*}$ is optimal batch quantity [piece], $L$ annual needs [piece/a], $s_{\text {Men }}$ order change costs $[€], s_{O b d}$ processing costs per piece [€/piece], $p$ interest rate of tied-up capital [1/a], $s_{\text {Mat }}$ material costs per piece [€/ piece], $R C$ available time [day/a], $S T$ material flow rate, $t_{e l}$ time per unit [min/piece], $K A P$ daily capacities [h/day].

These models are applicable when there is no fluctuation on the relation market-producer. There are neither distributions of production and demand processes considered nor the stochastic character of the mentioned processes.

\section{CASE STUDY OF CALCULATING THE OPTIMAL BATCH QUANTITY OF A PRODUCT}

Company $\mathrm{X}$, which is a supplier to a car components manufacturer, found it increasingly difficult to be competitive on the global market due to excessively long manufacturing lead times and too high product prices.

The company's management organised a creativity workshop [13] to [15] in order to identify urgent measures, whose implementation would improve their market competitiveness.

The results of the creativity workshop showed that it would be necessary to do the following in the company:

- $\quad$ significantly reduce the inventory in entry and exit warehouses, and on disposal locations within the production,

- $\quad$ significantly reduce the lead times of orders.

After the presentation of the results of the creativity workshop, management decided that they would first solve the problem of large stocks (i.e. tied-up capital), which significantly raise the price of products (i.e. non-competitiveness) [16] to [18].

A project team was established in the company, in order to analyse the causes of large stocks and to propose possible solutions.

Team members analysed inventories in all warehouses. Together with the heads of warehouses and the planners of production, they concluded that the batch quantities are defined on the basis of the experience of planners (i.e. estimates), which lead either to excessive stocks or a shortage of goods.

\begin{tabular}{|l|c|c|}
\hline \multicolumn{3}{|c|}{ Product 1: Shield } \\
\hline Operations: & $\begin{array}{c}\text { Time per unit: } \\
t_{e 1} \text { [min/piece] }\end{array}$ & $\begin{array}{c}\text { Setup time: } \\
T_{p}[\mathrm{~min}]\end{array}$ \\
\hline 10-CNC milling & 1.40 & 120 \\
\hline 20-washing & 2.22 & 15 \\
\hline 30-examination & 2.05 & 25 \\
\hline 40-assembly of the tube & 0.30 & 10 \\
\hline TOTAL & 5.97 & 170 \\
\hline
\end{tabular}

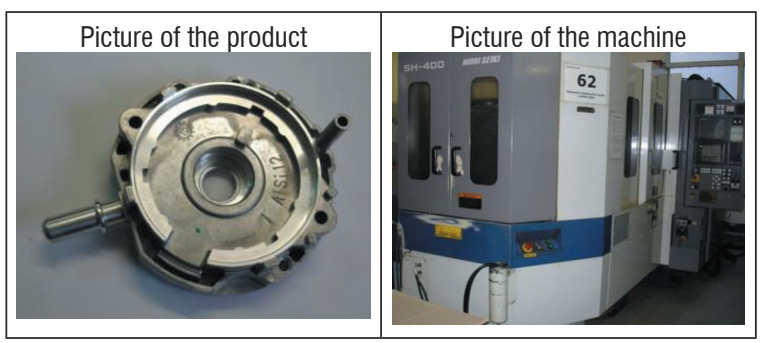

\begin{tabular}{|l|c|c|}
\hline \multicolumn{3}{|c|}{ Product 2: Left suspension support } \\
\hline Operations: & $\begin{array}{c}\text { Time per unit: } \\
t_{e 1} \text { [min/piece] }\end{array}$ & $\begin{array}{c}\text { Setup time: } \\
T_{p}[\mathrm{~min}]\end{array}$ \\
\hline 10-CNC milling I & 27.50 & 210 \\
\hline 20-CNC milling II & 6.50 & 30 \\
\hline 30-examination-measurements & 0.50 & 10 \\
\hline 40-assembly of bearings & 1.05 & 15 \\
\hline TOTAL & 35.55 & 265 \\
\hline
\end{tabular}

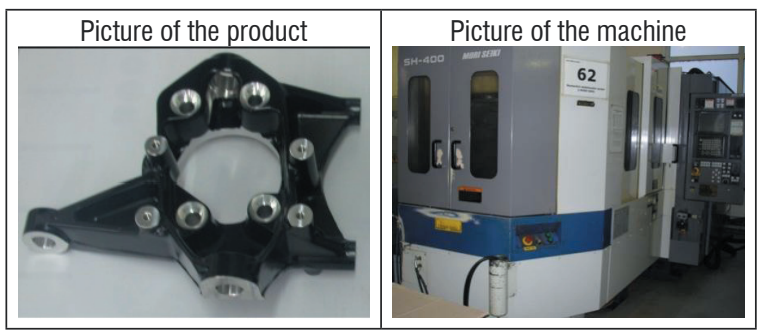

Fig. 7. $t_{\mathrm{e} 1}$ and $T_{p}$ times for shield and suspension support

The project team contacted the experts for help in solving the problem of over- and understocking of goods. Experts suggested that project team could use Eqs. (4) and (12) in order to calculate the optimal batch quantities of products.

It was agreed that the project team would calculate the optimal batch quantities by using both equations and find differences between the results of Eq. (4) and Eq. (12), and finally calculate additional annual costs to thus determine the advantages of using the Eq. (4) or Eq. (12). 
The project team decided that the first experimental calculation of the optimal batch quantity would be carried out for two products:

- Product 1: Shield;

- Product 2: Left suspension support.

The project team obtained the following data from the technology routings for both products:

- Data on times per unit $t_{e l}$ and setup times $T_{p}$ (Fig. 7).

- Other data, required for calculation of optimal product batch (Table 2), were obtained from various departments in the company.

Table 2. Data from company departments

\begin{tabular}{lcc}
\hline PRODUCT & Product 1 & Product 2 \\
\hline Sum of order changes $\Sigma s_{\text {Men }}[€]$ & 226 & 196 \\
\hline Costs of execution per piece $\Sigma s_{I V}[€ /$ piece] & 3.65 & 45.5 \\
\hline $\begin{array}{l}\text { Costs of material per piece [€/piece] } \\
\text { (incorporated in the costs of execution) }\end{array}$ & 1.52 & 29 \\
\hline Annual needs $L$ [piece/a] & 15000 & 1500 \\
\hline Available time $R C$ [day/a] & 250 & 250 \\
\hline Interest rate of tied-up capital $p[1 / \mathrm{a}]$ & 20 & 20 \\
\hline Daily capacities KAP [h/day] & 16 & 16 \\
\hline Material flow rate ST [-] & 3 & 3 \\
\hline
\end{tabular}

In order to assess the usability of the basic and extended model for the calculation of optimal batch quantity for both products, the project team decided that it would carry out the following:

- Calculation of optimal batch quantity for Products

1 and 2 using the basic and extended model:

- basic model:

$$
x_{O p t}=\sqrt{\frac{2 \cdot L \cdot s_{M e n}}{s_{O b d} \cdot p}}
$$

- extended model:

$$
x_{O p t}^{*}=\sqrt{\frac{2 \cdot L \cdot s_{M e n}}{s_{O b d} \cdot p+\frac{\left(s_{M a t}+s_{O b d}\right) \cdot L \cdot p}{60 \cdot R C} \cdot S T \cdot \sum \frac{t_{e l}}{K A P}}} .
$$

- Calculation of batch lead times for Products 1 and 2 using the basic and extended model:

- basic model:

$$
T_{O}=S T \cdot T_{I z v}, \quad T_{I z v}=\frac{\sum\left(T_{p}+t_{e 1} \cdot x_{O p t}\right)}{60 \cdot K A P},
$$

- extended model:

$$
T_{O}{ }^{*}=S T \cdot T_{I z v}{ }^{*}, \quad T_{I z v}^{*}=\frac{\sum\left(T_{p}+t_{e 1} \cdot x_{O p t}^{*}\right)}{60 \cdot K A P} .
$$

- Calculation of costs per product unit using the basic and extended model:
- basic model:

$$
s_{K o s}=s_{O b d}+s_{T o}+s_{\mathrm{Pre}}+\frac{s_{M e n}}{x_{O p t}},
$$

where $s_{K o s}$ are costs per product unit [€/piece], $s_{T o}$ costs of tied-up capital per product unit during the lead time $\left[€ /\right.$ piece], and $s_{P r e}$ costs of tied-up capital per product unit during interoperation time $[€ /$ piece $]$,

$s_{T o}=\frac{\left(s_{M a t}+s_{O b d}\right) \cdot p}{2} \cdot \frac{T_{O}}{R C}, \quad s_{\mathrm{Pr} e}=\frac{s_{O b d} \cdot p \cdot x_{O p t}}{2 \cdot L}$,

- extended model:

$$
\begin{gathered}
s_{K o s}^{*}=s_{O b d}^{*}+s_{T o}^{*}+s_{\mathrm{Pr} e}^{*}+\frac{s_{M e n}}{x_{O p t}^{*}} \\
s_{T o}^{*}=\frac{\left(s_{M a t}+s_{O b d}\right) \cdot p}{2} \cdot \frac{T_{O}^{*}}{R C}, \quad s_{\mathrm{Pr} e}^{*}=\frac{s_{O b d} \cdot p \cdot x_{O p t}^{*}}{2 \cdot L} .
\end{gathered}
$$

- Calculation of difference of costs per product unit:

$$
\Delta s_{K o s}=s_{K o s}-s_{K o s}^{*} .
$$

The calculations were made with MS Excel software. The results are shown in Table 3 .

The project team charted the influence of the batch quantity on the product costs (Fig. 8).

The results listed in Table 3 and Fig. 8 led the project team to the following conclusions:

- The calculated optimal batch quantities of both products are significantly different from the current estimated batch quantities. Due to this fact, the storage costs are high.

- Batch lead times are too long.

- The technology routing of Product 1 defines the short times per unit te1; diagrams on Fig. 8 show that at the transition from the basic to the extended model for calculation of the optimal batch quantity, the batch quantity is only slightly reduced and the total costs of tied-up capital are only slightly higher (if the total time te 1 is small, the basic model can be used for calculation of optimal batch quantity).

- The technology routing of Product 2 defines the long times per unit te1; diagrams on Fig. 8 show that at the transition from the basic to extended model of calculation, the batch quantity is considerably reduced and the total costs of tiedup capital are much higher (if the total time te1 
is large, extended model must be used for the calculation of optimal batch quantity).

- The basic model for calculation of optimal batch quantity does not take into account the tying-up of capital in production, and thus the optimal batch quantities are bigger than in the extended model.

Table 3. Results of calculations of optimal batch quantities for both products

\begin{tabular}{lcccc}
\hline \multirow{1}{*}{ CALCULATION } & \multicolumn{1}{c}{$\begin{array}{c}\text { Product 1: } \\
\text { SHIELD }\end{array}$} & \multicolumn{3}{c}{$\begin{array}{c}\text { Product 2: } \\
\text { SUSPENSION } \\
\text { SUPPORT }\end{array}$} \\
\cline { 2 - 5 } & \multicolumn{2}{c}{ Model } & \multicolumn{2}{c}{ Model } \\
\cline { 2 - 5 } & Basic & Extended & Basic & Extended \\
\hline $\begin{array}{l}\text { Optimal batch quantity } x \\
\text { [piece] }\end{array}$ & 3048 & 1896 & 255 & 163 \\
\hline Batch lead time $T_{0}$ [day] & 57.40 & 35.90 & 38.88 & 25.25 \\
\hline $\begin{array}{l}\text { Costs per product unit } s_{\text {Kos }} \\
\text { [€/piece] }\end{array}$ & 3.92 & 3.89 & 48.20 & 47.95 \\
\hline $\begin{array}{l}\text { Difference of costs per } \\
\text { product unit } \Sigma s_{\text {Kos }}[€ / \text { piece] }\end{array}$ & 0.03 & \multicolumn{2}{c}{0.25} \\
\hline
\end{tabular}

At the presentation of results, the company management agreed that the project team would continue its work in order to reduce lead times of orders.

\section{CONCLUSION}

This paper explains how to calculate the optimal batch quantity of a product (production is within the company) using the known basic and developed extended models; the latter, in addition to the costs of changing the batch (i.e. order) and storage costs, also takes into account the costs of interoperation time and the costs of execution of operations.

The project team in the company, which is a supplier of car components manufacturer, carried out some experiments, whose results have shown when to use the basic model and when to use the expanded model for the calculation of the optimal batch quantity. Further experiments in electro-mechanical industry will be needed for reliable decision making regarding the selection of the basic or extended model.

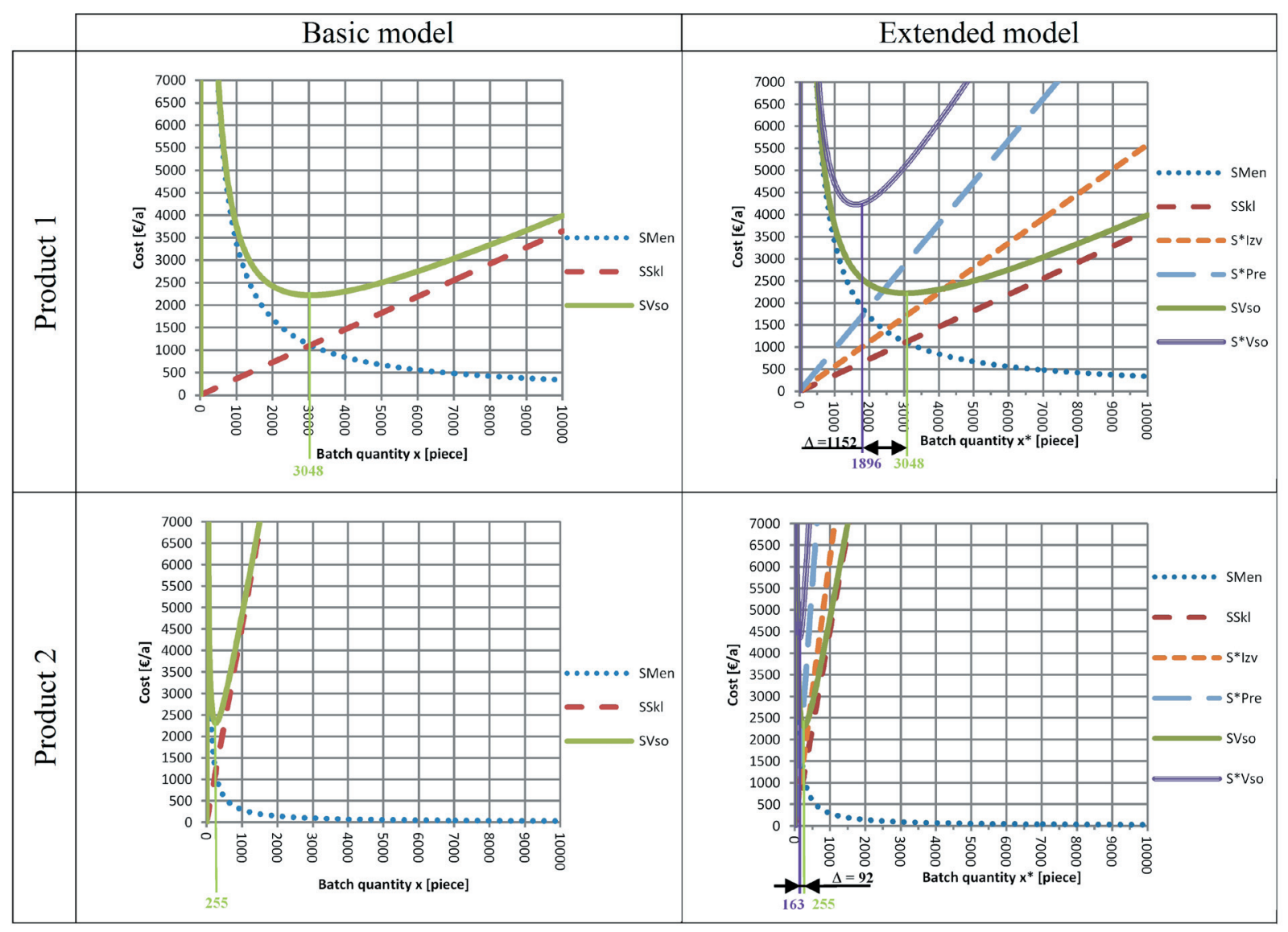

Fig. 8. Dependency diagrams costs vs. batch quantity for Products 1 and 2 
The model also needs to be further developed requiring a connection between the optimal quantities procuring materials in warehouses.

The company management decided for the project team to carry out also an AS-IS analysis of value flow for existing batch quantities. After a transition to optimal batches, the project team will repeat the value flow analysis for the same two products and find leadtime savings.

\section{REFERENCES}

[1] Heizer, J., Render, B. (2001). Principles of Operations Management, $6^{\text {th }}$ ed., Prentice Hall, Upper Saddle River.

[2] Fogarty, W.D., Blackstone, H.J., Hoffman, R.T. (1991). Production and Inventory Management (2nd ed.). Cengale Learning, Stamford.

[3] Slack, N., Chambers, S., Harland, C., Harrison, A., Johnson, R. (1995). Operations Management. Pitman Publishing, London.

[4] Aggteleky, B. (1990). Fabrikplanung, Band 3, Carl Hanser Verlag, München, Wien.

[5] Wiendahl, H.P. (2008). Betriebsorganistion für Ingenieure. Carl Hanser Verlag, München, Wien.

[6] Härdler, J. (2012). Betriebswirtschaftslehre für Ingenieure. Carl Hanser Verlag, München, Wien.

[7] Muller, M. (2011). Essentials of Inventory Management, $2^{\text {nd }}$ edition, Amacom, New York.

[8] Piasecki, D.J. (2009). Inventory Management Explained: A Focus on Forecasting, Lot Sizing, Safety Stock, and Ordering Systems. Ops Publishing, Kenosha.

[9] Vollman, E.T., Berry, L.W., Whybark, D.C., Jacobs, F.R. (2005). Manufacturing Planning and Control Systems. McGrow-Hill, New York.
[10] Wiendahl, H.P. (1994). Load-Oriented Manufacturing Control. Springer-Verlag, London.

[11] Arnold, D., Furmans, K. (2009). Materialfluss in Logistiksystemen. Springer Verlag, Heidelberg, DOI:10.1007/978-3-642-01405-5.

[12] Nyhuis, P., Fronla, P. (2012). Durchlauforientierte Lösgrössenbestimmung, from http://www. enzyklopaedie-der-wirtschaftsinformatik.de/, accessed at 2012-01-19.

[13] Rihar, L., Kušar, J., Duhovnik, J., Starbek, M. (2010). Teamwork as a Precondition for Simultaneous Product Realization. Concurrent Engineering: Research and Applications, vol. 18, no. 4, p. 261-273, DOI:10.5545/ sv-jme.2012.420.

[14] Kušar, J., Berlec, T., Žefran, F., Starbek, M. (2010). Reduction of Machine Setup Time. Strojniški vestnik - Journal of Mechanical Egineering, vol. 56, no. 12, p. 833-845.

[15] Rihar, L., Kušar, J., Gorenc, S., Starbek, M. (2012). Teamwork in the Simultaneous Product Realisation. Strojniški vestnik - Journal of Mechanical Egineering, vol. 58, no. 9, p. 534-544.

[16] Buchmeister, B., Pavlinjek, J., Palčič, I., Polajnar, A. (2008). Bullwhip Effect Problem in Supply Chains. Advances in production engineering \& management, vol. 3, no. 1, p. 45-55.

[17] Palčič, I., Buchmeister, B., Polajnar, A. (2010). Analysis of Innovation Concepts in Slovenian Manufacturing Companies. Strojniški vestnik - Journal of Mechanical Egineering, vol. 56, no. 12, p. 803-810.

[18] Božičković, R., Radošević, M., Ćosić, I., Soković, M., Rikalović. A. (2012). Integration of Simulation and Lean Tools in Effective Production Systems Case Study, Strojniški vestnik - Journal of Mechanical Egineering, vol. 58, no. 11, p. 642-652, DOI:10.5545/ sv-jme.2012.387. 